DOI: https://doi.org/10.11144/Javeriana.upsy16-4.pmrp

\title{
The Predictive and Moderating role of Psychological Flexibility in the Development of Job Burnout
}

\section{El rol predictivo y moderadores de la flexibilidad psicológica en el burnout}

Received: 24 March 2015 | Accepted: 08 March 2017

\author{
Francisco J. RuIz \\ Fundación Universitaria Konrad Lorenz, Colombia \\ ORCID: http://orcid.org/0000-0001-8863-1111 \\ Paula Odriozola-González \\ Universidad Europea del Atlántico, España
}

\begin{tabular}{lcc}
\hline a Correspondance & autor. & E-mail: \\
franciscoj.ruizj@konradlorenz.edu.co &
\end{tabular}

How to cite: Ruiz, F. J., \& Odriozola-González, P. (2017). The predictive and moderating role of psychological flexibility in the development of job burnout. Universitas Psychologica, 16(4), 1-8. https://d oi.org/10.11144/Javeriana.upsy16-4.pmrp

\begin{abstract}
Recent research has found that psychological flexibility, the key construct of the Acceptance and Commitment Therapy (ACT) model of mental health and behavioral effectiveness, is related to, and longitudinally predicts, a wide range of work-related outcomes. Less research, however, has been dedicated to explore the role of psychological flexibility as a protecting factor for the development of burnout syndrome. The current study examined whether: (a) general psychological flexibility and work-related psychological flexibility accounted for additional variance in burnout symptoms relative to work factors and other work-related constructs such as work engagement, work satisfaction, and psychological empowerment; and (b) work-related psychological flexibility moderated the relationship between exhaustion and cynicism. A cross-sectional study was conducted with 209 Spanish workers from different companies who completed questionnaires assessing the constructs of interest. Hierarchical regression analyses showed that psychological flexibility and work-related psychological flexibility accounted for additional variance in burnout symptoms. The moderator analysis showed that the relationship between exhaustion and cynicism was higher among participants with low levels of work-related psychological flexibility as compared to participants with high levels. These results suggest that interventions aiming to increase psychological flexibility might prevent the development of burnout syndrome.

Keywords

psychological flexibility; job burnout; acceptance and commitment therapy; emotional exhaustion; cynicism.
\end{abstract}

\section{RESUMEN}

La investigación ha mostrado que la flexibilidad psicológica, el constructo central del modelo de salud mental y eficacia conductual de la terapia de aceptación y compromiso (ACT), está relacionada y predice longitudinalmente un amplio rango de variables relacionadas con el trabajo. Menor grado de investigación se ha dedicado a explorar el rol de la flexibilidad psicológica como factor protector del desarrollo del síndrome de burnout. El presente estudio analizó si: (a) la flexibilidad 
psicológica general y la flexibilidad psicológica relacionada con el trabajo explicaban varianza adicional de los síntomas de burnout comparado con factores laborales y constructos como compromiso laboral, satisfacción laboral y empoderamiento psicológico; y (b) la flexibilidad psicológica relacionada con el trabajo moderaba la relación entre agotamiento y cinismo. Se realizó un estudio transversal con 209 trabajadores españoles de diferentes empresas que completaron cuestionarios que miden los constructos de interés. El análisis de regresión jerárquica mostró que la flexibilidad psicológica general y la flexibilidad psicológica relacionada con el trabajo explicaron varianza adicional de los síntomas de burnout. El análisis de moderación mostró que la relación entre agotamiento y cinismo fue mayor entre los participantes con niveles bajos de flexibilidad psicológica relacionada con el trabajo comparado con los participantes con niveles altos. Los resultados sugieren que las intervenciones que tienen como objetivo incrementar la flexibilidad psicológica podrían prevenir el desarrollo del síndrome de burnout.

Palabras clave

flexibilidad psicológica; burnout; terapia de aceptación y compromiso; agotamiento emocional; cinismo.

Job burnout is a psychological syndrome involving chronic strain due to a misfit between the worker and the job, which can lead to physical and psychological problems (e.g., Shirom \& Melamed, 2005) and to decreased cognitive functioning (e.g., Deligkaris, Panagopoulou, Montgomery, \& Masoura, 2014). Job burnout is usually described according to three dimensions: (a) overwhelming exhaustion, (b) feelings of cynicism and detachment from the job, and (c) a sense of ineffectiveness and lack of accomplishment. These three dimensions seem to differ in their origins. The sense of inefficacy is more related to lack of resources or skills to do the job properly, whereas exhaustion and cynicism seem to arise in the presence of work overload and social conflict. Specifically, exhaustion is a basic stress response to the job context that usually leads to engagement in cynicism as an avoidant coping strategy to confront work demands (Maslach, 2003). However, these attempts to distance oneself from job exhaustion make the situation worse because they can lead to negative consequences for clients, colleagues, and the company to the extent that cynicism usually causes the worker to make the minimum effort and to withdraw from the job.

Psychological flexibility (PF) is the core concept of the acceptance and commitment therapy (ACT; Hayes, Strosahl, \& Wilson, 1999) model of psychological health and behavioral effectiveness. PF is the ability to stay in the present moment, mindfully aware of private experiences (e.g., thoughts, feelings, physiological sensations, memories, etc.), and committed to valued goals (Hayes, Luoma, Bond, Masuda, \& Lillis, 2006; Moran, 2015). A great amount of empirical evidence has supported the adaptive role of psychological flexibility and its role as the process of change in ACT interventions (Hayes et al., 2006; Ruiz, 2012). In relation to the workplace, more than 20 studies have shown that psychological flexibility correlates with, and longitudinally predicts, a wide range of work-related outcomes, and that ACT interventions increase employees' mental health and reduce burnout (see a review in Moran, 2015).

The ACT model suggests that psychological flexibility is contextually controlled and, therefore, can vary across different contexts. For instance, a person may show high levels of psychological flexibility in the context of sport competitions (e.g., training as much as possible even in the presence of physical pain or stress), but at the same time, she may show low levels of psychological flexibility in the work context by allowing herself to be controlled by her feelings of boredom and exhaustion instead of by her values. Accordingly, psychological flexibility measures tailored to specific contexts may be strongly associated with specific variables from that context than with general measures. Therefore, specific measures of psychological flexibility have been developed during the last few years, including the Workrelated Acceptance and Action Questionnaire (Bond, Lloyd, \& Guenole, 2013).

The current study aimed to analyze the role of both general and work-related psychological flexibility in job burnout. Questionnaires assessing these constructs as well as work engagement, psychological empowerment, 
The Predictive and Moderating role of Psychological Flexibility in the Development of Job...

and job satisfaction were administered to 209 workers. Firstly, we hypothesized that hierarchical regression analyses would reveal that general and work-related psychological flexibility account for incremental variance of job burnout relative to demographic variables, work factors, and the remaining work-related psychological constructs. Secondly, we hypothesized that work-related psychological flexibility would act as a moderator in the relationship between exhaustion and cynicism. Specifically, we expected that the relationship would be stronger for participants with lower levels of work-related psychological flexibility. Conversely, participants with high levels of work-related psychological flexibility would less likely respond to feelings of exhaustion by engaging in an experiential avoidance strategy such as cynical behaviors.

\section{Method}

\section{Participants}

The sample consisted of 209 employees from the south of Spain, with age ranging between 18 and 60 years $(M=36.1, S D=12.13)$. Approximately $52 \%$ of participants were men $(N=109)$ and $48 \%$ were women $(N=100)$. The relative educational level of the participants was as follows: $23.4 \%$ primary studies, $48.8 \%$ mid-level study graduates, and $27.8 \%$ college graduates or currently taking university courses. The mean number of years spent in their current job was $7.94(S D=9.68)$, working $35.5(S D=$ 10.82) hours per week: $29.6 \%$ worked by day with a lunch break, 20.2\% had an intensive working schedule, $14.8 \%$ had flextime, $12.3 \%$ worked half a day, $10.3 \%$ had a fixed shift, and $12.8 \%$ had a rotating shift.

Regarding their working status, $16.7 \%$ of participants were in an illegal situation or without compensation, $16.3 \%$ were temporary workers, $25.1 \%$ had a contract for between 6 months and 5 years, and $41.9 \%$ had an indefinite contract. With respect to participants' hierarchy within the organization, 79\% were line-level workers, 5.9\% supervisors, $7.3 \%$ middle management, $4.4 \%$ managers, and $2.4 \%$ corporate managers.

\section{Instruments}

Acceptance and Action Questionnaire - II (AAQII; Bond et al., 2011; Spanish version by Ruiz, Langer, Luciano, Cangas, $\mathcal{E}$ Beltrán, 2013)

The AAQ-II is a 7-item, 7-point Likert-type scale $(1=$ never true, 7 = always true) that measures general psychological inflexibility or psychological flexibility depending on how it is scored. The AAQ-II has shown a onefactor solution, good internal consistency, and discriminant, convergent and divergent validity. The direction of the scores on the AAQ-II in this study was set so that higher scores indicated higher psychological flexibility. In this study, the AAQ-II showed an alpha coefficient of 0.89.

Work-related Acceptance and Action Questionnaire (WAAQ; Bond et al., 2013; Spanish version by Ruiz Eु Odriozola-González, 2014)

The WAAQ is a 7-item, 7-point Likert-type scale $(1=$ never true, $7=$ always true $)$ that measures psychological flexibility in relation to the workplace. Higher scores indicate greater levels of work-related psychological flexibility. The WAAQ has excellent internal consistency and good convergent validity. In this study, the WAAQ showed an alpha coefficient of 0.92 .

Maslach Burnout Inventory-General Survey (MBI-GS, Schaufeli, Leiter, Maslach, Eु Jackson, 1996; Spanish version by Salanova, Schaufeli, Llorens, Peiró, Eु Grau, 2000)

The MBI-GS is a 16-item, 7-point Likert-type scale $(0=$ never, $6=$ every day $)$, generic measure of burnout that is independent of vocational aspects. It contains three factors: Exhaustion, Cynicism, and Professional Efficacy. 
Higher scores on Exhaustion and Cynicism and lower scores on Professional Efficacy are indicative of greater levels of burnout. The MBIGS has shown adequate psychometric properties. In this study, alpha coefficients were 0.88 , 0.8, and .84 for Exhaustion, Cynicism, and Professional Efficacy, respectively.

Utrecht Work Engagement Scale (UWES; Schaufeli, Bakker, Ë Salanova, 2006; Spanish version by Salanova et al., 2000)

The UWES is a 15-item, 7-point Likert-type scale $(1=$ never true, 7 = always true) that aims to measure work engagement. It contains three factors: Vigor, Dedication, and Absorption. The UWES has shown appropriate psychometric properties in several studies. In this study, the UWES showed excellent internal consistency, with an alpha coefficient of 0.93 .

Overall Job Satisfaction Scale (OJS; Warr, Cook, E. Wall, 1979; Spanish version by Munduate, 1984)

The OJS is a 15-item, 7-point Likert-type scale $(1=$ very unsatisfied, $7=$ very satisfied $)$ that provides a general measure of job satisfaction. It contains two factors: Intrinsic Satisfaction and Extrinsic Satisfaction. The OJS has shown good psychometric properties. In this study, the OJS showed an excellent internal consistency, with an alpha coefficient of 0.91 .

\section{Psychological Empowerment Inventory (PEI;} Spreitzer, 1995)

The PEI is a 12-item, 7-point Likert-type scale $(1=$ completely disagree, $7=$ completely agree $)$ that measures psychological empowerment in a workplace context. It contains four factors: Meaning, Competence, Self-determination, and Impact. The PEI has shown good psychometric properties and validity. For the present study, we back-translated the PEI into Spanish. Alpha coefficients of the subscales were .88 for
Meaning, 0.81 for Competence, 0.82 for Selfdetermination, and 0.78 for Impact.

\section{Procedure}

The sample was recruited from undergraduate labor science students and personal contacts. The only inclusion criterion was that participants reported being working in some company. Individuals were interviewed individually and those who provided informed consent were given a questionnaire packet including the selfreport instruments in the order listed above. Upon completion of the study, we debriefed participants about the aims of the study and thanked them for their participation.

\section{Data analysis}

All data analyses were conducted with SPSS22 ${ }^{\circ}$. To test the first hypothesis, three hierarchical regression analyses were conducted to assess the associations of demographic variables, work-related factors, and psychological constructs with each of the burnout facets (i.e., exhaustion, cynicism, and professional efficacy). Step 1 entered demographic variables (age, gender, educational level), work-related variables (seniority, work schedule, working hours, working status, and hierarchy within the organization), and the psychological constructs job satisfaction, work engagement, and psychological empowerment. Step 2 entered general psychological flexibility and work-related psychological flexibility.

To test the second hypothesis, a regressionbased path analysis was used with the aid of the computational tool PROCESS (Hayes, 2013). A simple moderation analysis was conducted to analyze whether work-related psychological flexibility moderated the relationship between exhaustion and cynicism. Moderator effect was deemed significant if the $95 \%$ confidence intervals (CI) for those effects did not include zero. 


\section{Results}

\section{Testing Hypothesis 1}

Table 1 shows the results from the hierarchical regression analyses conducted for each burnout facet. With regard to Exhaustion, the model in Step 1 accounted for 29\% of the variance. In Step 2, General Psychological Flexibility showed to be a significant negative predictor of Exhaustion $(\beta$ $=-0.35)$, and the model accounted for $10 \%$ of additional variance as compared to Step 1.

Respecting Cynicism, the model in Step 1 accounted for $34 \%$ of the variance. In Step 2, General Psychological Flexibility was a significant negative predictor $(\beta=-0.16)$. The model accounted for $37 \%$ of the variance.

Lastly, regarding Professional Efficacy, the model in Step 1 accounted for 33\% of the variance. In Step 2, Work-related Psychological Flexibility was a significant positive predictor $(\beta$ $=0.44)$, and the model accounted for $15 \%$ of additional variance as compared to Step 1 .
TABLE 1

Hierarchical Regression Analysis of Exhaustion, Cynicism, and Professional Efficacy

\begin{tabular}{|c|c|c|c|c|c|c|}
\hline & \multicolumn{2}{|c|}{ Exhaustion } & \multicolumn{2}{|c|}{ Cynicism } & \multicolumn{2}{|c|}{$\begin{array}{c}\text { Professional } \\
\text { efficacy }\end{array}$} \\
\hline & $\beta$ & Adj. $R^{2}$ & $B$ & Adj. $R^{2}$ & $\beta$ & Adj. $R^{2}$ \\
\hline \multicolumn{7}{|l|}{ STEP 1} \\
\hline Gender & 0.07 & & -0.05 & & 0.12 & \\
\hline Age & -0.17 & & -0.13 & & -0.02 & \\
\hline Educational level & 0.07 & & -0.04 & & -0.09 & \\
\hline Seniority & 0.05 & & 0.07 & & 0.04 & \\
\hline Work schedule & -0.08 & & -0.03 & & -0.05 & \\
\hline Working hours & $0.15^{*}$ & & 0.13 & & 0.01 & \\
\hline Working position & -0.06 & & -0.05 & & -0.02 & \\
\hline Hierarchy in organization & 0.05 & & -0.01 & & -0.09 & \\
\hline Job satisfaction & $-0.44 * * *$ & 0.29 & $-0.31 * * *$ & 0.34 & -0.15 & 0.33 \\
\hline Work engagement & $-0.39 * * *$ & & $-0.31 * * *$ & & $0.41^{* * *}$ & \\
\hline Psy chological empowerment & $0.27 * * *$ & & -0.04 & & $0.33^{* * *}$ & \\
\hline \multicolumn{7}{|l|}{ STEP 2 } \\
\hline Gender & 0.06 & & -0.05 & & $0.11^{*}$ & \\
\hline Age & $-0.19 *$ & & -0.14 & & -0.05 & \\
\hline Educational level & 0.09 & & -0.03 & & -0.07 & \\
\hline Seniority & 0.11 & & 0.09 & & 0.08 & \\
\hline Work schedule & -0.12 & & -0.05 & & -0.06 & \\
\hline Working hours & $0.15^{*}$ & & $0.12 *$ & & 0.02 & \\
\hline Working position & -0.08 & & -0.07 & & 0 & \\
\hline Hierarchy in organization & 0.04 & & -0.02 & 0.37 & -0.07 & \\
\hline Job satisfaction & $-0.38 * * *$ & & $-0.3^{* * *}$ & & -0.05 & \\
\hline Work engagement & $-0.35 * * *$ & 0.39 & $-0.27 * *$ & & $0.24 * *$ & 0.48 \\
\hline Psy chological empowerment & $0.32 * * *$ & & 0.01 & & $0.21^{*}$ & \\
\hline Psychological flexibility & $-0.35 * * *$ & & $-0.16^{*}$ & & -0.05 & \\
\hline Psy chological flexibility work & -0.01 & & -0.07 & & $0.44 * * *$ & \\
\hline
\end{tabular}

Source: own work.

\section{Testing Hypothesis 2}

Table 2 shows that the effect of Exhaustion on Cynicism was considerably higher among participants with low levels of Work-related Psychological Flexibility as compared to participants with high levels (interaction coefficient: Exhaustion $\mathrm{x}$ Workrelated Psychological Flexibility $=-0.016, p$ $=0.007)$. Specifically, at very low scores on the WAAQ $\left(10^{\text {th }}\right.$ percentile), the effect of Exhaustion on Cynicism was 0.672. This effect decreased as scores on the WAAQ increased, with an effect of 0.327 for the $90^{\text {th }}$ percentile. 


\section{TABLE 2}

Moderation Analysis of the Effect of Exhaustion on Cynicism and the Conditional Effect of Exhaustion on Cynicism at Values of Work-Related Psychological Flexibility

\begin{tabular}{|c|c|c|c|c|}
\hline Antecedent & & Coefficient & $S E$ & $p$ \\
\hline $\mathrm{X}$ (Exhaustion) & $\mathrm{b}_{1}$ & 1.064 & 0.213 & $<0.001$ \\
\hline M (Work PF) & $\mathrm{b}_{2}$ & -0.004 & 0.073 & 0.955 \\
\hline $\mathrm{X} \times \mathrm{M}$ & $b_{3}$ & -0.016 & 0.006 & 0.007 \\
\hline \multirow[t]{3}{*}{ Intercept } & $\mathrm{i}_{1}$ & 4.181 & 2.862 & 0.146 \\
\hline & & \multicolumn{3}{|l|}{$R^{2}=0.443$} \\
\hline & & \multicolumn{3}{|c|}{$F(5.197)=31.386, p<0.001$} \\
\hline WAAQ values & & Coefficient & $S E$ & $p$ \\
\hline $25\left(10^{\text {th }}\right.$ percentile $)$ & & 0.672 & 0.084 & $<0.001$ \\
\hline $31\left(25^{\text {th }}\right.$ percentile $)$ & & 0.578 & 0.062 & $<0.001$ \\
\hline $37\left(50^{\text {th }}\right.$ percentile $)$ & & 0.484 & 0.055 & $<0.001$ \\
\hline $42\left(75^{\text {th }}\right.$ percentile $)$ & & 0.406 & 0.065 & $<0.001$ \\
\hline $47\left(90^{\text {th }}\right.$ percentile $)$ & & 0.327 & 0.083 & $<0.001$ \\
\hline
\end{tabular}

Note.PF = Psychological Flexibility;

WAAQ $=$ Work-Related Acceptance and Action Questionnaire.

Source: own work.

\section{Discussion}

Job burnout is usually described in terms of three dimensions: emotional exhaustion, cynicism, and sense of ineffectiveness and lack of accomplishment. According to Maslach (2003), these dimensions differ in their origins. On the one hand, exhaustion seems to arise in the presence of work overload and social conflict and usually leads to engage in cynicism as an avoidant coping strategy. On the other hand, the sense of professional inefficacy seems to be more related to the lack of skills to do the job properly. Irrespective of the origin of burnout components, psychological (in)flexibility might be involved in the development of job burnout. For instance, individuals displaying psychological flexibility might not react to the stress provoked by work factors or the sense of not having the skills to do the job properly in a pernicious way, and just will focus on the relevant aspects of the tasks to be done. Conversely, individuals displaying psychological inflexibility might react to the same stressors by engaging in experiential avoidance strategies such as worrying, ruminating, thought suppression, distraction, etc. This way, the discomfort is usually maintained and extended while, at the same time, the individuals' attention is not focused on the task so that the job is not done properly. Once these individuals experience emotional exhaustion, they might engage in feelings of cynicism and detachment from the job as additional experiential avoidance strategies that make things worse on the long term.

The current study was designed to test the latter assumptions. Since psychological flexibility is contextually controlled and can vary across different contexts, we tested the role of general and work-related psychological flexibility in job burnout. Hierarchical regression analyses showed that the inclusion of both constructs accounted for additional variance of burnout components: an additional $10 \%$ of variance in exhaustion, $3 \%$ in cynicism, and $15 \%$ in professional efficacy. Specifically, general psychological flexibility was a significant negative predictor of exhaustion $(\beta=$ $-0.35)$ and cynicism $(\beta=-0.16)$, whereas workrelated psychological flexibility was a significant positive predictor of professional efficacy $(\beta=$ 0.44). These results support the need to evaluate both general and work-related psychological flexibility. In relation to the model of burnout development (Maslach, 2003), work-related psychological flexibility emerged as a moderator of the relationship between exhaustion and cynicism. Specifically, the results showed that exhaustion would lead to the development of cynicism in participants with low levels of workrelated psychological flexibility more easily than in participants with high levels of work-related psychological flexibility.

The main limitation of this study is the cross-sectional design used, which precludes determining causal relationships among variables, as such relationships cannot be assumed without establishing temporal precedence. Two additional limitations are worth mentioning. Firstly, as all data were obtained using self-report measures, relationships among psychological constructs might be artificially inflated. Secondly, it could be that psychological flexibility would be more relevant for some kinds of jobs than for others. However, the sample used in this study was not sufficiently large to explore this possibility. According to 
the above-mentioned limitations, future studies might explore whether the current findings are confirmed in a longitudinal design with a larger sample and using additional measures (e.g., behavioral measures).

In conclusion, the results of the current study highlight the role of psychological flexibility in the development of job burnout and suggest that interventions aiming to increase psychological flexibility, such as ACT protocols, might prevent the development of burnout syndrome.

\section{References}

Bond, F. W., Hayes, S. C., Baer, R. A., Carpenter, K. M., Guenole, N., Orcutt, H. K., \& ... Zettle, R. D. (2011). Preliminary psychometric properties of the Acceptance and Action Questionnaire - II: A revised measure of psychological inflexibility and experiential avoidance. Behavior Therapy, $42(4), 676-688$.

Bond, F. W., Lloyd, J., \& Guenole, N. (2013). The Work-related Acceptance and Action Questionnaire (WAAQ): Initial psychometric findings and their implications for measuring psychological flexibility in specific contexts. Journal of Occupational and Organizational Psychology, 86(3), 331-347.

Deligkaris, P., Panagopoulou, E., Montgomery, A. J., \& Masoura, E. (2014). Job burnout and cognitive functioning: A systematic review. Work and Stress, 28(2), 107-123.

Hayes, A. F. (2013). Introduction to mediation, moderation, and conditional process analysis. A regression-based approach. New York: Guilford Press.

Hayes, S. C., Luoma, J. B., Bond, F. W., Masuda, A., \& Lillis, J. (2006). Acceptance and commitment therapy: Model, processes and outcomes. Behaviour Research and Therapy, 44(1), 1-25.

Hayes, S. C., Strosahl, K. D., \& Wilson, K. G. (1999). Acceptance and Commitment Therapy. An experiential approach to behavior change. New York: Guilford Press.
Maslach, C. (2003). Job burnout: New directions in research and intervention. Current Directions in Psychological Science, 12(5), 189-192.

Moran, D. J. (2015). Acceptance and commitment therapy in the workplace. Current Opinion in Psychology, 2, 26-31.

Munduate, L. (1984). Motivación en el trabajo [Motivation at work]. Madrid: Ministerio de Trabajo y Seguridad Social.

Ruiz, F. J. (2012). Acceptance and commitment therapy versus traditional cognitive behavioral therapy: A systematic review and meta-analysis of current empirical evidence. International Journal of Psychology and Psychological Therapy, 12(3), 333-357.

Ruiz, F. J., Langer, A. I., Luciano, C., Cangas, A. J., \& Beltrán, I. (2013). Measuring experiential avoidance and psychological inflexibility: The Spanish translation of the Acceptance and Action Questionnaire-II. Psicothema, 25(1), 123-129.

Ruiz, F. J., \& Odriozola-González, P. (2014). The Spanish version of the Work-related Acceptance and Action Questionnaire (WAAQ). Psicothema, 26(1), 63-68.

Salanova, M., Schaufeli, W. B., Llorens, S., Peiró, J. M., \& Grau, R. (2000). Desde el "burnout" al "engagement": iuna nueva perspectiva? [From burnout to engagement: A new perspective?]. Revista de Psicología del Trabajo y las Organizaciones, 16(2), 117-134.

Schaufeli, W. B., Bakker, A. B., \& Salanova, M. (2006). The measurement of work engagement with a short questionnaire: A cross-national study. Educational and Psychological Measurement, 66(4), 701-716.

Schaufeli, W. B., Leiter, M. P., Maslach, C., \& Jackson, S. E. (1996). The Maslach Burnout Inventory-General Survey. In C. Maslach, S. E. Jackson, \& M. P. Leiter (Eds.), Maslach Burnout Inventory. Palo Alto, CA: Consulting Psychologists Press.

Shirom, A., \& Melamed, S. (2005). Does burnout affect physical health? A review of the evidence. In A. S. G. Antoiou \& C. L. Cooper (Eds.), Research companion 
Francisco J. Ruiz, Paula Odriozola-González.

to organizational health psychology (pp. 599-622). Cheltenham, UK: Edward Elgar.

Spreitzer, G. M. (1995). Psychological empowerment in the workplace: Dimensions, measurement, and validation. Academy of Management Journal, 38(5), 1442-1465.

Warr, P. B., Cook, J. D., \& Wall, T. D. (1979). Scales for the measurement of some work attitudes and aspects of psychological wellbeing. Journal of Occupational Psychology, $52(2), 129-148$.

\section{Notes}

* Research article. 